\title{
BMJ Open Mapping instruments for assessing and stratifying frailty among community- dwelling older people: a scoping review
}

Luiz Eduardo Lima Andrade (D), Beatriz Souza de Albuquerque Cacique New York, Rafaella Silva dos Santos Aguiar Gonçalves, Sabrina Gabrielle Gomes Fernandes, Álvaro Campos Cavalcanti Maciel

To cite: Andrade LEL, New York BSdAC, Gonçalves RSdSA, et al. Mapping instruments for assessing and stratifying frailty among communitydwelling older people: a scoping review. BMJ Open 2021;11:e052301. doi:10.1136/ bmjopen-2021-052301

- Prepublication history for this paper is available online. To view these files, please visit the journal online (http://dx.doi. org/10.1136/bmjopen-2021052301).

Received 14 April 2021 Accepted 13 November 2021

A Check for updates

(c) Author(s) (or their employer(s)) 2021. Re-use permitted under CC BY-NC. No commercial re-use. See rights and permissions. Published by BMJ.

Physiotherapy, Federal University of Rio Grande do Norte, Natal, Rio Grande do Norte, Brazil

Correspondence to Luiz Eduardo Lima Andrade; luizeduardofisio@gmail.com

\section{ABSTRACT}

Objective To map in the current literature instruments for the assessment and stratification of frailty in communitydwelling older people, as well as to analyse them from the perspective of the Brazilian context.

Design Scoping review.

Study selection The selection of studies took place between March and April 2020. Includes electronic databases: Medline, Latin American and Caribbean Literature in Health Sciences, Scopus, Web of Science and Cumulative Index of Nursing and Literature Health Alliance, in addition to searching grey literature.

Data extraction A data extraction spreadsheet was created to collect the main information from the studies involved, from the title to the type of assessment and stratification of frailty.

Results In summary, 17 frailty assessment and stratification instruments applicable to communitydwelling older people were identified. Among these, the frailty phenotype of Fried et al was the instrument most present in the studies (45.5\%). The physical domain was present in all the instruments analysed, while the social, psychological and environmental domains were present in only 10 instruments.

Conclusions This review serves as a guideline for primary healthcare professionals, showing 17 instruments applicable to the context of the community-dwelling older people, pointing out advantages and disadvantages that influence the decision of the instrument to be used. Furthermore, this scoping review was a guide for further studies carried out by the same authors, which aim to compare instruments.

\section{INTRODUCTION}

Assessing and managing the health of the older people have been presented as a strong goal of health professionals in the field of geriatrics and gerontology. ${ }^{1}$ The Ministry of Health of Brazil recommends the systematic evaluation of this public, including in $\mathrm{PHC}^{2}$ since with the demographic transition that has been occurring all over the world, older people are becoming increasingly long lived and this is a factor that is also associated with

\section{Strengths and limitations of this study}

- This is the first scoping review in the literature to analyse the instruments available for screening and stratifying frail older adults in the community, which will serve as a guide for Primary Healthcare (PHC) professionals during the assessment of the older adults.

- The research strategy includes five electronic databases with peer-reviewed literature, as well as a wide variety of sources of grey literature.

- A limitation of the study is the search for studies with only an observational design. It involves research using instruments, questionnaires, interviews, which most resembles the reality of PHC workers. Clinical research with a greater degree of methodological robustness and assessment equipment/instruments are not feasible to be developed in the context of PHC.

the emergence of health problems, such as frailty. $^{3}$

Frailty is a clinical condition in which there is a decrease in biological reserve and resistance to stressors, resulting from changes in various physiological systems, leading to the individual's vulnerability ${ }^{4}$ and other adverse health outcomes, such as risk of falls, disability, hospitalisation and mortality. ${ }^{56}$ To date, there is still no consensus on a single definition of frailty for clinical use ${ }^{6}$ since such impairment can be either physical, psychological or a combination of both. ${ }^{7}$ As a result, several concepts and ways of measuring the syndrome are available in the literature, ${ }^{5-10}$ which often makes it difficult to make comparisons and choose the one that best fits the epidemiological reality of each region.

The prevalence of frailty varies greatly according to the context of analysis and the assessment instrument that is used. ${ }^{11}$ Studies carried out in Brazil found that the prevalence of frailty in the older people varied between $8.7 \%$ and $47.2 \% .^{12}{ }^{13}$ There is still no 
consensus on which instrument should be used to identify and stratify frailty in the older people, since many instruments only consider the physical aspects of the condition, others take into account psychological and cognitive issues. ${ }^{11}$ Such divergence makes it even more difficult to identify this condition early, especially in PHC, since in this context, the use of instruments of low technological complexity and low cost is indicated. ${ }^{14}$

In this perspective, it is necessary to investigate simpler instruments for the identification of frailty, facilitating its use in care environments such as $\mathrm{PHC},{ }^{11}$ since identification in the early stages allows a better prognosis of reversal of frailty. ${ }^{1}$ This is the reason why low-cost, easyaccess and applicable assessment tools for the screening and stratification of frailty are so important.

Thus, it is important to search the literature for instruments for screening and stratifying frailty in communitydwelling older people, in an attempt to guide PHC health professionals towards early identification, prevention and treatment of this public. Professionals trained in adequate numbers and with the necessary resources are essential aspects for effective care, as well as the identification and prevention of frailty in older people. ${ }^{3}$

Therefore, this scoping review aims to identify the instruments available in the literature for the assessment and stratification of frailty in community-dwelling older people, as well as analysing them from the perspective of the Brazilian context. With these data, health professionals and managers will have a guide containing the main instruments they can use in the search for early identification of frailty, as well as assisting in the action planning and decision-making in health regarding this topic. This paper will constitute the first stage of a larger research that aims to compare assessment instruments for the frailty among older people in the community.

\section{METHODS}

The scoping review methodological design was chosen as a research design, as it has methodological rigour and serves to map and analyse the scientific literature, with the additional advantage of including methodologically heterogeneous evidence, in addition to consulting stakeholders to validate this evidence. ${ }^{15}$

\section{Identification of the research question}

This topic was developed through research in the literature about 'frailty in the older adults in primary health care', along with discussions by the research team on the subject in question. In the pursuit for the research question, the Population, Concept and Context strategy was used, a methodology proposed by the Joanna Brigs institute, ${ }^{16}$ thus defined as: Population (older adults individuals aged 60 or over); Concept (frailty assessment instruments); Context (community/PHC) the following research question was defined: What are the instruments available in the literature for assessing and stratifying frailty in community-dwelling older people?
Some instruments for the assessment of the older adults are known to the scientific community ${ }^{12}{ }^{17}$; however, many of them, due to their complexity, were not developed to be applied in the context of PHC, ${ }^{519}$ that is, in community-dwelling older adults. Therefore, the mapping of this research aims only at instruments of low technological complexity that can be applied to the population inserted in this context.

\section{Identifying relevant studies}

This stage was based on meetings with the research team, which defined the planned approach: the eligibility criteria of the studies, the selected databases, as well as the research strategy with the respective descriptors.

Eligibility criteria: full articles published without restriction of language or date of publication were included, in which the primary or secondary objective was the assessment of frailty in community-dwelling older people using instruments. In this study, the older people will be considered to be an individual aged 60 or over.

Editorials, experience reports, review protocols, clinical trials, reflection studies and reviews were excluded; papers that do not present abstract and full text online. Studies addressing evaluations through laboratorial or higher technological clinical exams were excluded.

The identification of relevant studies was conducted by searching electronic databases of scientific literature such as: Medline, Latin American and Caribbean Literature in Health Sciences (LILACS), Scopus, Web of Science and Cumulative Index of Nursing and Literature Health Alliance (CINAHL). The choice of these databases was due to the wide coverage of studies both internationally and nationally, with public access or available through a library, in addition to the large collection of manuscripts related to the theme of ageing. The search strategy used in these databases was defined by the research team and collaborators and it is detailed in table 1 .

An analysis of all reference lists of the included studies was also carried out, in order to identify additional relevant studies. In addition, information was captured,

\begin{tabular}{ll}
\hline Table 1 & Database search strategy \\
\hline Search & Query \\
\hline \#1 & (frail OR frailty) \\
Comparator & (aging OR elderly) \\
\#2 & \\
Comparator & ("independent living" OR "community \\
\#3 & dwelling") \\
Comparator & ("Observational Study") \\
\#4 & $\begin{array}{l}\text { \#1 AND \#2 AND \#3 AND \#4 } \\
\text { Comparator }\end{array}$ \\
\#5 & $\begin{array}{l}\text { There was no restriction on language and } \\
\text { date of publication, only the study design } \\
\text { Limit }\end{array}$ \\
& $\begin{array}{l}\text { that was delimited by the choice of the } \\
\text { comparator \#4 }\end{array}$ \\
\hline
\end{tabular}


researches were made on a variety of sources of grey literature, such as thesis and dissertation banks, annals of national and international congresses on geriatrics and gerontology and in the reference list of selected articles, to identify studies, reports and conference abstracts relevant to this review. For the analysis of grey literature, an extra researcher was invited (BSACNY). This researcher was informed about the research objectives and descriptors used, in order to do an independent search in the grey literature. Restrictions were not applied in relation to the period of publication of the studies in the analysed bases nor in relation to the language of the research.

\section{Selection of studies}

The selection of studies took place in two stages: first, there was a review of the title and abstract, after the elimination of duplicate articles, for this stage, the articles were added on the Rayyan platform (https://rayyan.qcri. org). The second stage consisted of reviewing the full text of the studies that were selected in the first stage. For both stages, the process took place in pairs, where two researchers (RSSAG and SGGF) duly trained and oriented about the eligibility criteria of the studies performed the screening in a blind and independent way and, in case of doubts or divergences in the selection, there was a third evaluator (LELA) who judged and resolved any selection problems encountered. The study selection period was from February to April 2020.

In the first stage, the two researchers (RSSAG and SGGF) independently selected the tracked studies based on the title and abstract. The eligibility criteria was tested on a sample of abstracts before the start of the abstract review to ensure that they were robust enough to capture any articles that may be related to instruments for assessing of frailty in community-dwelling older adults. Any articles that were considered relevant by one or both reviewers were included in the review of the full text.

In the second stage, the two researchers (RSSAG and SGGF) read the studies selected in the first stage in full to determine whether they met the inclusion and exclusion criteria. In order to determine the agreement between evaluators, as well as to support the rigour of the research.

\section{Data collection}

Data were collected using a semistructured form developed by the research team, which aims to collect relevant information from the studies included in this research. This form was previously tested by all reviewers before its final application, to ensure that the information captured was accurate.

Data collection was carried out in pairs, where two reviewers (RSSAG and SGGF) independently extracted data from all included studies. At the end, individual collections were compared in order to visualise possible discrepancies and, if there were any, they were reviewed and analysed by the research group, thus ensuring consistency among reviewers.
The questionnaire had items such as: year of publication, type of publication (eg, original research), country, study objective, population and sample, characteristics of the type of evaluation instrument used, number of items in the instrument, number of domains of the instrument, form of instrument assessment (interview, self-report, questionnaire), form of screening and/or stratification of frailty: descriptive, score (with appropriate cut-off points), percentiles.

The assessment instruments included were divided according to table 2 into objectives, subjective and mixed. This was a didactic way to facilitate the understanding of instruments that use a questionnaire or interview (subjective evaluation), tools that use performance measures (objective evaluation) or both forms of evaluation (mixed). A quality assessment was not included in the mandate of this scope review. As this is a research with data secondary to published articles, there was no involvement of the patient and the public for data collection.

\section{Patient and public involvement \\ No patient involved.}

\section{RESULTS}

The search in the databases and grey literature resulted in a total of 2668 studies. After excluding duplicates, 1357 studies were evaluated by peers for eligibility in the title and abstract. After applying the inclusion and exclusion criteria, 72 articles were read in full and, of these, only 55 were selected for final analysis in this research (figure 1). The characteristics of the included studies are shown in table 2.

A total of 141115 older people comprised the sum of the samples of the included studies, the smallest study being composed of 26 participants, while the study with the largest sample recruited more than 72000 participants. Regarding the gender of the participants, most studies used samples that involved both sexes (91\%), with the exception of five studies that were composed of only women (table 2).

In general, 17 instruments for assessing and stratifying frailty applicable to community-dwelling older people were analysed, with Fried's frailty criteria being the most used instrument, being present in 25 studies $(45.5 \%)$ (table 2). Of the 55 articles included, 39 were published after 2015 (71\%), most were from American continents: South America (32.8\%) or North America (21.9\%), and the most used study design cross-sectional $(47.3 \%)$ (table 2).

Although they have a similar purpose, which is the assessment of frailty, the instruments had very heterogeneous structures, such as the number of items, where the instrument with the lowest quantity had three items (Study of Osteoporotic Fractures-Frailty Index (SOF-FI) and the highest quantity had 36 items (FI), in addition to an instrument that did not specify the number of items as it was a broad and robust assessment (Comprehensive 
Table 2 Details of the studies included according to the author, study design, sample size, instrument for assessing frailty and the prevalence of frailty in the older people.

\begin{tabular}{|c|c|c|c|}
\hline Author (year) & Study design & Sample size & Frailty assessment tool \\
\hline Maltais et al ${ }^{41} 2019$ & Prospective cohort & 113 older people of both sexes ( $\geq 70$ years) & Phenotype of frailty \\
\hline Serra-Prat et al/2 2019 & Cross-sectional & 324 older people of both sexes ( $\geq 75$ years) & Phenotype of frailty \\
\hline lizaka $^{44} 2018$ & Cross-sectional & 128 older people of both sexes ( $\geq 65$ years) & Phenotype of frailty \\
\hline Li et $a l^{45} 2018$ & Prospective cohort & 2438 older people of both sexes ( $\geq 65$ years) & $\begin{array}{l}\text { Modified Phenotype of } \\
\text { frailty }\end{array}$ \\
\hline Shimada et $\mathrm{al}^{20} 2019$ & Cross-sectional & 4072 older people of both sexes ( $\geq 65$ years) & $\begin{array}{l}\text { Phenotype of frailty; } \\
\text { NCGG-FAT }\end{array}$ \\
\hline Sampaio et al ${ }^{47} 2015$ & Cross-sectional & 211 older people women ( $\geq 60$ years) & $\mathrm{KC}$ \\
\hline Garre-Olmo et al ${ }^{48} 2013$ & Prospective cohort & 875 older people of both sexes ( $\geq 74$ years) & $\begin{array}{l}\text { Disability-free frailty } \\
\text { phenotype }\end{array}$ \\
\hline Hasegawa et $\left.a\right|^{51} 2019$ & Cross-sectional & 308 older people of both sexes ( $\geq 65$ years) & KC \\
\hline Satake et al ${ }^{52} 2017$ & Prospective cohort & 5542 older people of both sexes ( $\geq 65$ years) & $\mathrm{KC}$ \\
\hline Ballew et al ${ }^{53} 2017$ & Cross-sectional & 341 older people of both sexes ( $\geq 66$ years) & Phenotype of frailty \\
\hline Zaslavsky et al ${ }^{54} 2017$ & Prospective cohort & 876 older people women ( $\geq 65$ years) & Phenotype of frailty \\
\hline Monin et $a l^{55} 2016$ & Prospective cohort & 2524 older people of both sexes ( $\geq 65$ years) & Phenotype of frailty \\
\hline Espinoza and Hazuda ${ }^{56} 2015$ & Cross-sectional & 394 older people of both sexes (65-80 years) & Phenotype of frailty \\
\hline Drubbel et $\left.a\right|^{57} 2013$ & Cross-sectional & 1549 older people of both sexes ( $\geq 60$ years) & GFI e FI \\
\hline Yao et $a l^{58} 2011$ & Prospective cohort & 94 older people of both sexes ( $\geq 70$ years) & Phenotype of frailty \\
\hline Kiely et al ${ }^{59} 2009$ & Prospective cohort & 765 older people of both sexes ( $\geq 70$ years) & $\begin{array}{l}\text { Phenotype of frailty; SOF- } \\
\text { Frailty Index }\end{array}$ \\
\hline Turusheva et al ${ }^{65} 2016$ & Prospective cohort & 611 older people of both sexes ( $\geq 65$ years) & $\begin{array}{l}\text { Cumulative model (Puts } \\
\text { model); Steventik-Slaets } \\
\text { model (using the GFI); } \\
\text { Phenotype of frailty }\end{array}$ \\
\hline Bastone et $a l^{66} 2015$ & Cross-sectional & 26 older people of both sexes ( $\geq 65$ years) & Phenotype of frailty \\
\hline Ruiz-Arregui et al ${ }^{67} 2013$ & Prospective cohort & 1124 older people of both sexes ( $\geq 70$ years) & Phenotype of frailty \\
\hline Giudici et a/68 2019 & Prospective cohort & 1679 older people of both sexes ( $\geq 70$ years) & Phenotype of frailty \\
\hline Lin et $a l^{33} 2018$ & Prospective cohort & 72127 older people of both sexes ( $\geq 65$ years) & $\mathrm{KC}$ \\
\hline Yeap et al 2012 & Prospective cohort & $\begin{array}{l}3447 \text { older people men aged between } 70 \text { and } \\
89 \text { years }\end{array}$ & FRAIL Scale. \\
\hline Xue et $a l^{69} 2008$ & Prospective cohort & $\begin{array}{l}420 \text { older people women aged between } 70-79 \\
\text { years }\end{array}$ & Phenotype of frailty \\
\hline Min et $a l^{70} 2006$ & Prospective cohort & 3207 older people of both sexes ( $\geq 65$ years) & VES-13 \\
\hline Pegorari et $a l^{71} 2013$ & Cross-sectional & 51 older people of both sexes ( $\geq 65$ years) & Phenotype of frailty \\
\hline McHugh et $\left.a\right|^{28} 2016$ & Prospective cohort & 624 older people of both sexes ( $\geq 65$ years) & Modified frailty phenotype \\
\hline Tian et $a l^{72} 2018$ & Cross-sectional & 1917 older people of both sexes ( $\geq 60$ years) & Phenotype of frailty \\
\hline Freitas and Soares ${ }^{73} 2019$ & Cross-sectional & 2972 older people of both sexes ( $\geq 65$ years) & CFVI-20 \\
\hline Fhon ${ }^{74} 2011$ & Cross-sectional & 240 older people of both sexes ( $\geq 60$ years) & EFS \\
\hline
\end{tabular}


Table 2 Continued

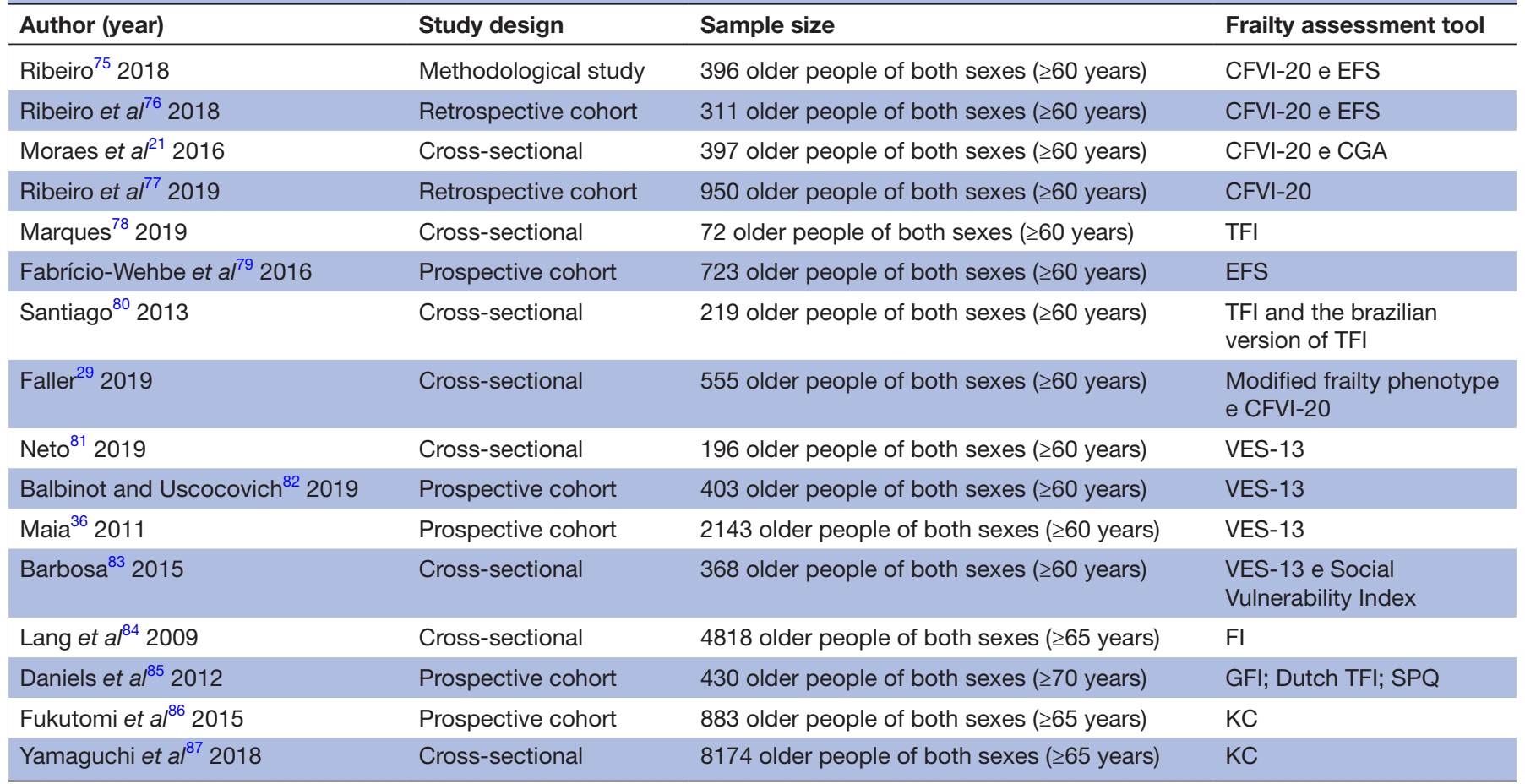

CFVI-20, Functional Clinical Vulnerability Index-20; CGA, Comprehensive Geriatric Assessment; EFS, Edmonton Frailty Scale; FI, Frailty Index; GFI, Groningen Frailty Indicator; KC, Kihon Check list; NCGG-FAT, National Center for Geriatrics and Gerontology-Functional Assessment Tool; SOF-Frailty Index, Frailty Index of Study of Osteoporotic Fractures; SPQ, Sherbrooke Postal Questionnaire; TFI, Tilburg Frailty Indicator; VES-13, Vulnerable Elders Survey.

Geriatric Assessment (CGA)). Regarding the evaluation time, only two studies reported these times, one being, ${ }^{20}$ which reported only the time for evaluating the cognitive part $(20 \mathrm{~min})$, and another, ${ }^{21}$ reported that the evaluation of one of the addressed instruments varied between 60 and $90 \mathrm{~min}$.

Regarding the domains, six instruments evaluate only physical questions (Phenotype of frailty, Modified Frailty Phenotype, 5-Frail, SOF-FI, Vulnerable Elders Survey (VES-13) and Frail Scale), one evaluates physical and cognitive questions (National Center for Geriatrics and Gerontology-Functional Assessment Tool (NCGG-FAT)), four evaluate physical, psychological and social issues (disability-free frailty phenotype, Groningen Frailty Indicator (GFI), Tilburg Frailty Indicator (TFI) and Sherbrooke Postal Questionnaire (SPQ)), the other instruments have more than three domains for assessing frailty. Of the 17 instruments analysed, two have the ability to predict mortality in the next 2 years (VES-13 and CGA) and six have the ability to predict prefrailty (Phenotype of Frailty, Modified Frailty Phenotype, 5-Frail, SOF-FI, FI, Puts Model and CGA). Of these instruments, 10 are validated in Brazil, and one (Clinical-Functional Vulnerability Index-20 (CFVI-20)) was developed in the country.

The prevalence of frailty was heterogeneous, varying from $3 \%$ to $52.7 \%$ between studies, this variation occurred both between different instruments, and even between the same instruments used in different studies (table 3).

\section{DISCUSSION}

This study used a systematic approach to map and synthesise the main instruments for screening and stratifying frailty in community-dwelling older people, in addition to analysing them from the perspective of the Brazilian context. The assessment of frailty is becoming a routine daily practice in the treatment of older people patients, ${ }^{22}$ so a guide with the tools that can trace such screening and stratification in the context of PHC is of paramount importance.

In summary, 55 articles became eligible for the study, with 17 different instruments present. The phenotype of frailty ${ }^{5}$ was the most used instrument in the articles, which also demonstrates a strong connection of the physical domain in the assessment of frailty in older people.

In the analysed articles, the physical domain was present in all instruments, while the other domains (social, psychological and environmental) were present in more recent instruments (Edmonton Frailty Scale (EFS), Disability-free frailty phenotype, GFI, CFVI-20, Kihon Check list (KC), NCGG-FAT, TFI, Puts model and SPQ). This may be related to the evolution of the concept of frailty, which in its early days was related strictly to physical issues ${ }^{5}$ and today, this concept involves multifactorial and systemic issues. ${ }^{11}$

Researches show that frailty is directly associated with factors other than physical functions, such as social, environmental and psychological. ${ }^{23-25}$ A study developed by 


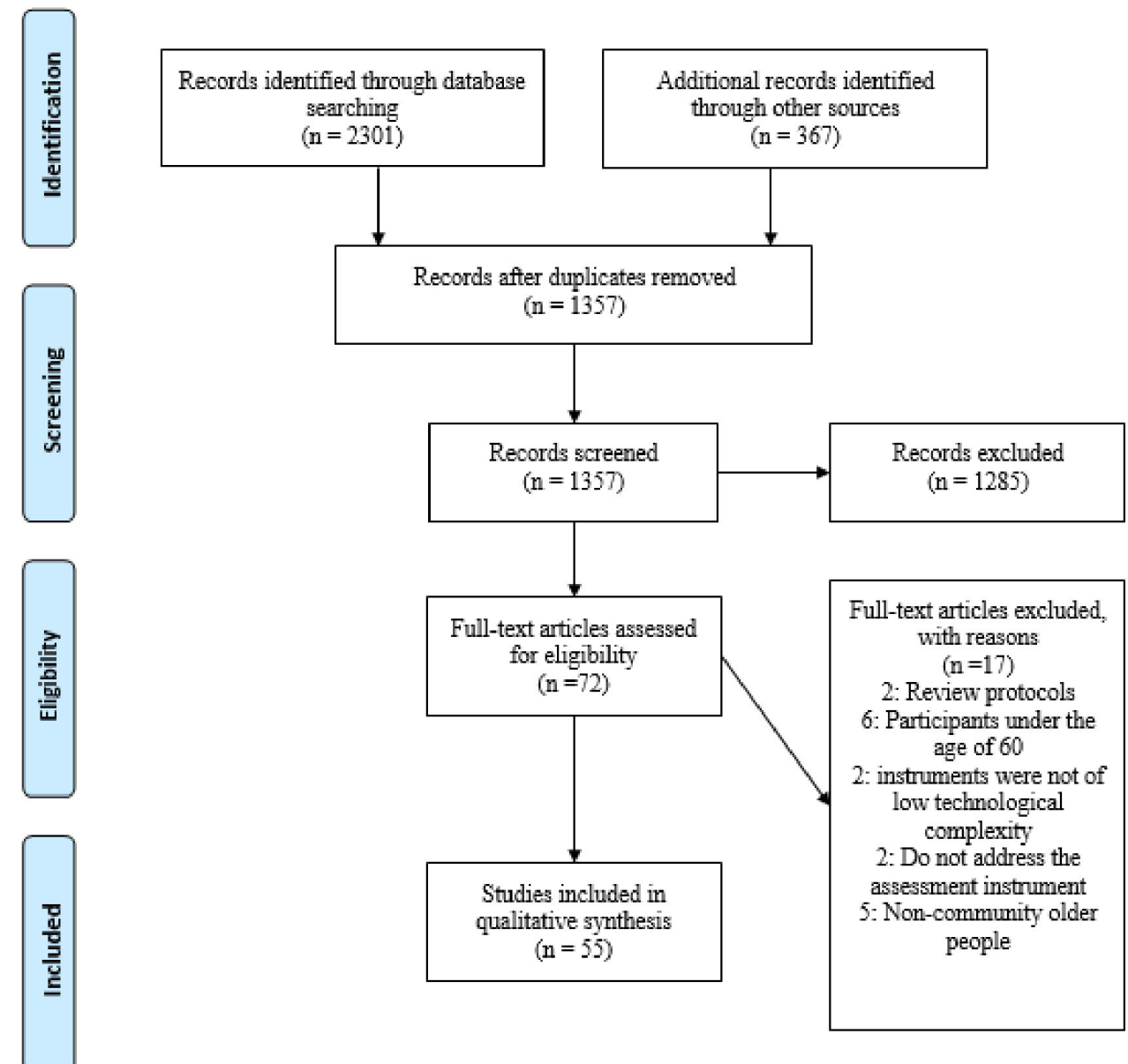

Figure 1 Selection diagram of studies involving instruments for screening and stratifying frailty in the older people.

Santiago $e t a l,{ }^{26}$ using the TFI, assessed 442 older people men and women and concluded that, if only the physical domain was considered, $0.3 \%$ of the sample would have frailty, when the social domain was added, the prevalence would increase to $2.9 \%$ and when analysing the three domains (physical, social and psychological), the prevalence would rise to $52 \%$. This reinforces the idea that frailty can arise not only from strictly physical issues, ${ }^{21}$ directly affecting the choice of the assessment instrument, since some assess only the physical domain.

Among the instruments analysed, there was a heterogeneous and multifaceted structure, this diversity provided methodological divergences both in the choice of the instrument, in the definition of the cut-off point for exposure to frailty, as well as in its prevalence among the samples, which compromise the comparison of studies. ${ }^{27}$ The survey carried out in this review found that there is still no gold standard tool for assessing frailty, the ones found in the papers are instruments that use diversified parameters. Even so, each instrument has advantages and disadvantages, therefore, it is highlighted that, for the proper choice of the instrument in the context of PHC, the focus should be on which type of screening is to be performed.

The assessment instruments were didactically categorised into objective, subjective and mixed. These forms of assessment corroborate the understanding of authors such as Tibess and de Oliveira, ${ }^{27}$ who point out that, for logistical reasons, questionnaires/interviews continue to be used frequently in older populations, although efforts have been made to increase the use of performance measures.

Some instruments such as phenotype of frailty and its modified version, ${ }^{52} 29$ for presenting an assessment of physical performance, require specific tools such as the manual dynamometer, while other instruments for presenting only subjective evaluation (through questionnaires or interviews) such as the CFVI-20 or VES-13 do not need more specific equipment. This can also influence the choice of the assessment instrument, since, in the context of PHC in the Brazilian reality, sometimes more specific devices are not available, and the assessment of frailty will be limited by tools that require such instruments.

Some questionnaires use questions about past times such as: 'In the last year, did you lose more than $5 \%$ of your body weight?', or about activities carried out in the previous week, self-perceived health issues based on past days (phenotype of frailty, Modified Frailty Phenotype, NCGG-FAT, KC, CFVI-20, CGA, EFS, disability-free frailty phenotype, Frail scale, FI, SOF, TFI and GFI), these questions are often influenced, in the older people population, 


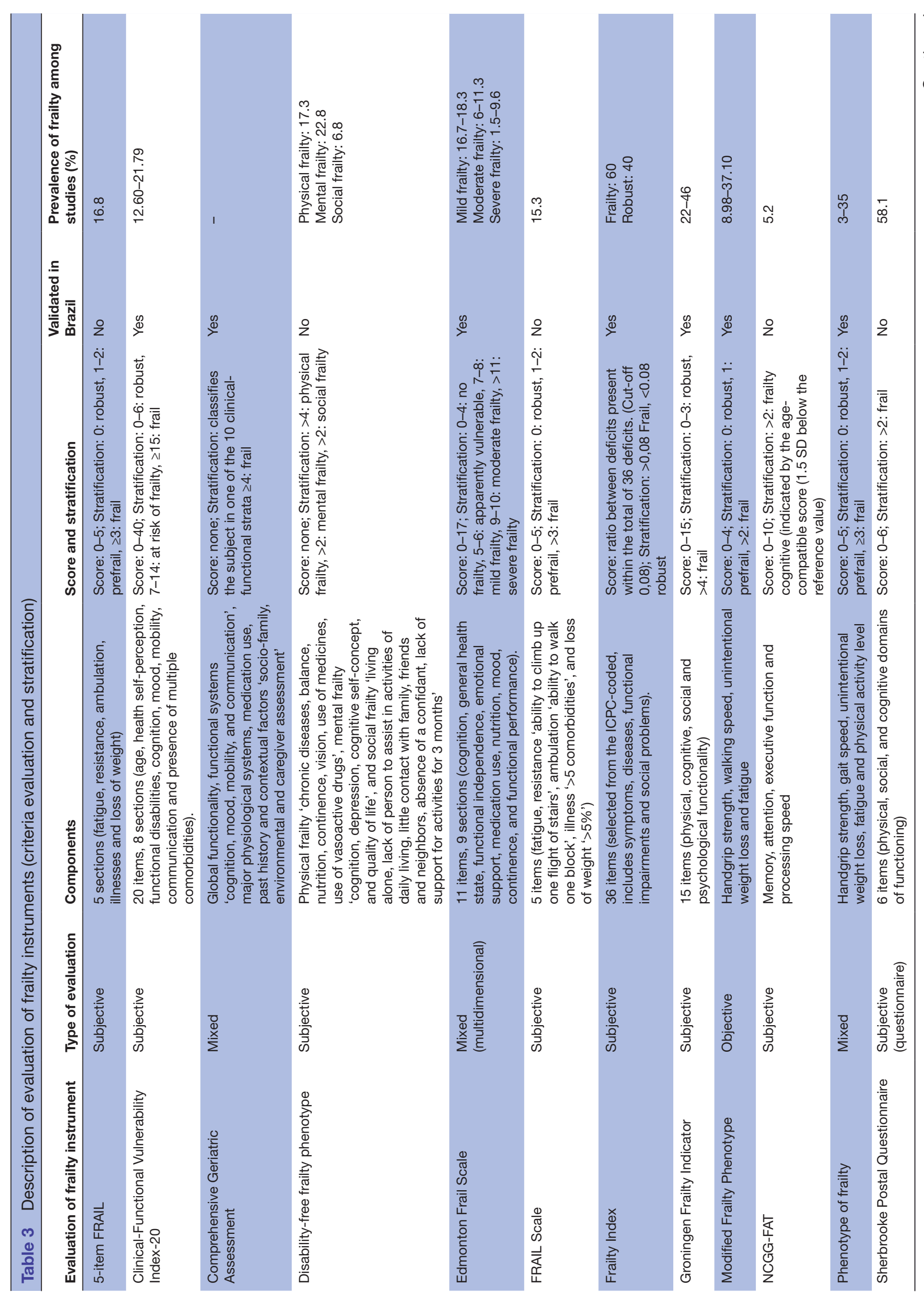


by memory bias. For this reason, authors such as Chang et $a l^{30}$ advise the use of instruments that objectively assess the physical performance of patients, avoiding this type of bias.

Despite being a progressive condition, frailty can be prevented and rehabilitated. ${ }^{31}$ In this context, the instruments that allow the identification of prefrailty (frailty phenotype, Modified Frailty Phenotype, 5-frail, SOF FI, puts model, CGA) have positive aspects and stand out, since, when diagnosed early, functional changes resulting from frailty may have a better prognosis. Thus, the reversal of the situation becomes more likely when interventions are applied in the initial phase of frailty. ${ }^{32}$

Among the instruments included in this research, it is analysed that 10 of them present validated measurements for Brazil in the assessment of frailty in communitydwelling older people (table 3). The Ministry of Health included in the new Health Handbook for the Elderly one of these questionnaires, the VES $13,{ }^{33} 34$ in an attempt to promote a practical form of screening frailty to healthcare professionals. PHC, since it has easy and fast application. The VES-13 is an effective instrument to identify the vulnerable commmunity-dwelling older people, with an emphasis on data regarding age, self-perceived health, presence of physical limitations and disabilities. ${ }^{35}$ The vulnerable older people was defined as that individual who is at risk of functional decline or death in 2 years. ${ }^{36}$

Most instruments were developed abroad, with the exception of CFVI-20. ${ }^{37}$ This tool was developed in the Brazilian context in a joint and interdisciplinary action, and is applicable in the outpatient and community setting. In addition to being a Brazilian tool, it was shown to be positively correlated to CGA, in addition to the results pointing to high values of validity and reliability. ${ }^{21}$

In the case of CGA, it is a very widespread instrument in Brazil and quite complete, as it evaluates the health of the older people in a global and multidisciplinary way, using various tools to achieve this goal. ${ }^{38}$ This completeness also reflects one of its disadvantages, since the instrument is very large, requiring about $60-90 \mathrm{~min}$ for application, in addition to requiring several professionals to complete it. ${ }^{21}$ This often leads to limitation of its use in the reality of Brazilian PHC. Thus, it is important that health professionals know other, faster ways of screening to improve the identification of the frailty in older people.

The screening instruments for application in PHC must respect the context in which they are inserted, therefore, they must be of short duration, when possible, be administered by other means such as telephone and also by different professionals, allowing the reach a greater number of individuals, still being accurate about adverse results. ${ }^{39}$

According to the Brazilian consensus on frailty in the older people ${ }^{11}$ the conceptual diversity of criteria and instruments reflects in areas such as assistance, teaching and research, making it difficult to choose instruments, compare results and compromise adequate training of professionals in the area. In this sense, this review becomes a guide since it 
highlights instruments available in the literature for assessing the community-dwelling older people and also presents which of these have validation (and/or cross-cultural adaptation) in Brazil.

A limitation of the study is the search for studies with only an observational design. We opted for this search restriction since in this type of study design, it involves research using instruments, questionnaires, interviews, which most resembles the reality of PHC workers. Clinical research with a greater degree of methodological robustness and assessment equipment/instruments are not feasible to be developed in the context of PHC.

The differential of this research is the mapping of instruments that evaluate not only frailty but its stratifications (nonfragile, prefrailty, frailty and robust), in addition to detailing of instruments that approach other constructs besides the physical function for the screening of frailty, such as: cognitive, social and psychological issues. Added to this, it also sought to analyse among the selected instruments those that have validity in Brazil, as well as to describe their potential for easy application, as suggested by previous studies. ${ }^{40}$

\section{Main learning}

The data from this research provide the understanding that choosing the appropriate instrument to assess frailty is not simple, given the lack of global consensus regarding the definition of this syndrome. However, there are instruments in the literature that are validated, simple and that provide the screening of frailty in community-dwelling older people. Therefore, the choice of this instrument will depend on the objectives outlined by the evaluators, as well as the domains that they seek to analyse for this screening.

\section{CONCLUSION}

The assessment of frailty in PHC can be performed by several instruments. This review served as a guideline for professionals in this area, demonstrating 17 instruments applicable to the context of the community-dwelling older people, pointing out advantages and disadvantages in deciding on the instrument of use.

From all the tools analysed in this study, ten of them are validated in Brazil and one was built in the country itself. As no instrument considered to be the gold standard was verified, the choice of the instrument will depend on which domains the evaluators want to address for the screening and stratification of frailty.

Furthermore, this scoping review was a guide for further studies carried out by the same authors, which aim to compare instruments for assessing frailty in PHC.

\section{Twitter Luiz Eduardo Lima Andrade @luizeduardofis}

Contributors LELA and ACCM: responsible for the overall content as the guarantor, substantial contributions to the conception or design of the work, or the acquisition, analysis or interpretation of data, drafting the work or revising it critically for important intellectual content, final approval of the version published. BSACNY, RSSAG and SGGF: collected, analysis and interpretation of data, drafting the work or revising it critically for important intellectual content, final approval of the version published.
Funding This study was financed by the Coordenação de Aperfeiçoamento de Pessoal de Nivel Superior - Brasil (CAPES) - Finance Code 001. The funders had nor role in study design, data collection and analysis, decision to publish, or preparation of the manuscript.

Competing interests None declared.

Patient and public involvement Patients and/or the public were not involved in the design, or conduct, or reporting, or dissemination plans of this research.

\section{Patient consent for publication Not applicable.}

Ethics approval This review did not require ethical approval as it consisted of analysing and collecting information from publicly available documents.

Provenance and peer review Not commissioned; externally peer reviewed.

Data availability statement Data sharing not applicable as no datasets generated and/or analysed for this study.

Open access This is an open access article distributed in accordance with the Creative Commons Attribution Non Commercial (CC BY-NC 4.0) license, which permits others to distribute, remix, adapt, build upon this work non-commercially, and license their derivative works on different terms, provided the original work is properly cited, appropriate credit is given, any changes made indicated, and the use is non-commercial. See: http://creativecommons.org/licenses/by-nc/4.0/.

ORCID iD

Luiz Eduardo Lima Andrade http://orcid.org/0000-0003-3835-4253

\section{REFERENCES}

1 Duarte YAO, Nunes DP, Andrade FB. Fragilidade em idosos no município de São Paulo: prevalência E fatores associados. Rev Bras Epidemiol 2018;21.

2 Brasil. Envelhecimento e saúde da pessoa idosa. Brasília: Ministério da Saúde, 2006.

3 Duarte YAO, Lebrão ML. Fragilidade e envelhecimento. In: Freitas EV, Py L, Cançado FAX, eds. Tratado de geriatria e gerontologia. 3 edn. Rio de Janeiro: Guanabara Koogan, 2013: 1285-98.

4 Campbell AJ, Buchner DM. Unstable disability and the fluctuations of frailty. Age Ageing 1997;26:315-8.

5 Fried LP, Tangen CM, Walston J, et al. Frailty in older adults: evidence for a phenotype. J Gerontol A Biol Sci Med Sci 2001;56:M146-56.

6 Rodríguez-Mañas L, Féart C, Mann G, et al. Searching for an operational definition of frailty: a Delphi method based consensus statement: the frailty operative definition-consensus conference project. J Gerontol A Biol Sci Med Sci 2013;68:62-7.

7 Morley JE, Vellas B, van Kan GA, et al. Frailty consensus: a call to action. J Am Med Dir Assoc 2013;14:392-7.

8 Bilotta C, Nicolini P, Casè A, et al. Frailty syndrome diagnosed according to the study of osteoporotic fractures (SOF) criteria and adverse health outcomes among community-dwelling older outpatients in Italy. a one-year prospective cohort study. Arch Gerontol Geriatr 2012;54:e23-8.

9 Aguayo GA, Donneau A-F, Vaillant MT, et al. Agreement between 35 published frailty scores in the general population. Am J Epidemiol 2017;186:420-34.

10 Mitnitski AB, Mogilner AJ, Rockwood K. Accumulation of deficits as a proxy measure of aging. ScientificWorldJournal 2001;1:323-36.

11 Lourenço RA, Moreira VG, Mello RGB, et al. Consenso brasileiro de fragilidade em idosos: conceitos, epidemiologia $E$ instrumentos de avaliação. Geriatr., Gerontol. Aging 2018;12:121-35.

12 Fabrício-Wehbe CSC, Veiga SF, et al. Adaptação cultural e validade da Edmonton Frail Scale - EFS em uma amostra de idosos brasileiros. Rev Latino-Am Enferm 2009;17.

13 Fhon JRS, Rosset I, Freitas CP, et al. Prevalence of falls among frail elderly adults. Rev Saude Publica 2013;47:266-73.

14 Unger JP, Killingsworth JR. Selective primary health care: a critical review of methods and results. Soc Sci Med 1986;22:1001-13.

15 Pham MT, Rajić A, Greig JD, et al. A scoping review of scoping reviews: advancing the approach and enhancing the consistency. Res Synth Methods 2014;5:371-85.

16 Joanna Briggs Institute (JBI). Methodology for JBI Scoping Reviews Joanna Briggs 2015. Australia: JBI, 2015.

17 Santiago LM, Luz LL, Mattos IE, et al. Cross-cultural adaptation of the Tilburg Frailty Indicator (TFI) for use in the Brazilian population. Cad Saude Publica 2012;28:1795-801.

18 Sewo Sampaio PY, Sampaio RAC, Yamada M, et al. Validation and translation of the Kihon checklist (frailty index) into Brazilian Portuguese. Geriatr Gerontol Int 2014;14:561-9. 
19 Baylis D, Bartlett DB, Syddall HE, et al. Immune-endocrine biomarkers as predictors of frailty and mortality: a 10-year longitudinal study in community-dwelling older people. Age 2013;35:963-71.

20 Shimada $\mathrm{H}$, Makizako $\mathrm{H}$, Lee $\mathrm{S}$, et al. Impact of cognitive frailty on daily activities in older persons. J Nutr Health Aging 2016;20:729-35.

21 Moraes EN, Carmo JA, Moraes FL. Índice de Vulnerabilidade Clínico Funcional-20 (IVCF-20): reconhecimento rápido do idoso frágil. Rev. Saúde Pública 2016;50:81.

22 Bruyère $O$, Buckinx $F$, Beaudart $C$, et al. How clinical practitioners assess frailty in their daily practice: an international survey. Aging Clin Exp Res 2017;29:905-12.

23 Sousa ACPA, Dias RC, Maciel ACC, et al. Frailty syndrome and associated factors in community-dwelling elderly in northeast Brazil. Arch Gerontol Geriatr 2012;54:e95-101.

24 Carneiro JA, Ramos GCF, Barbosa ATF, et al. Prevalência e fatores associados à fragilidade em idosos não institucionalizados. Rev Bras Enferm 2016;69:435-42.

25 Moreira VG, Lourenço RA. Prevalence and factors associated with frailty in an older population from the city of Rio de Janeiro, Brazil: the FIBRA-RJ study. Clinics 2013;68:979-85.

26 Santiago LM, Mattos IE. Prevalência e fatores associados à fragilidade em idosos institucionalizados das regiões Sudeste e Centro-Oeste do Brasil. Rev. bras. geriatr. gerontol. 2014;17:327-37

27 Tribess S, de Oliveira RJ. Biological fragility syndrome in the elderly: systematic review. Rev Salud Publica 2011;13:853-64.

28 McHugh JE, Dowling M, Butler A, et al. Psychological distress and frailty transitions over time in community-dwelling older adults. Ir J Psychol Med 2016;33:111-9.

29 Faller JW. Identificação da fragilidade em idosos em região de tríplice fronteira: estratégia para a promoção do envelhecimento ativo [thesis]. Ribeirão Preto: Escola de Enfermagem de Ribeirão Preto, 2019.

30 Chang SF, Yang RS, Lin TC, et al. The discrimination of using the short physical performance battery to screen frailty for communitydwelling elderly people. J Nurs Scholarsh 2014;46:207-15.

31 Gill TM, Baker DI, Gottschalk M, et al. A program to prevent functional decline in physically frail, elderly persons who live at home. N Engl J Med 2002;347:1068-74.

32 Xue QL. The frailty syndrome: definition and natural history. Clin Geriatr Med 2011;27:1-15.

33 Lin HR, Tsuji T, Kondo K, et al. Development of a risk score for the prediction of incident dementia in older adults using a frailty index and health checkup data: the JAGES longitudinal study. Prev Med 2018;112:88-96.

34 Yeap BB, Paul Chubb SA, Lopez D, et al. Associations of insulin-like growth factor-I and its binding proteins and testosterone with frailty in older men. Clin Endocrinol 2013;78:752-9.

35 Saliba D, Elliott M, Rubenstein LZ, et al. The vulnerable elders survey: a tool for identifying vulnerable older people in the community. J Am Geriatr Soc 2001;49:1691-9.

36 Maia FOM. Vulnerabilidade e envelhecimento: panorama dos idosos residentes no município de São Paulo - Estudo SABE [thesis]. São Paulo: Escola de Enfermagem, 2011.

37 Sousa-Santos AR, Afonso C, Moreira P, et al. Weakness: the most frequent criterion among pre-frail and frail older Portuguese. Arch Gerontol Geriatr 2018;74:162-8.

38 Moraes EN. Atenção Saúde do Idoso: Aspectos Conceituais. Brasília: Organização Pan-Americana da Saúde, 2012.

39 Gilardi F, Capanna A, Ferraro M, et al. Frailty screening and assessment tools: a review of characteristics and use in public health. Ann Ig 2018;30:128-39.

40 Dolenc E, Rotar-Pavlič D. Frailty assessment scales for the elderly and their application in primary care: a systematic literature review. Zdr Varst 2019;58:91-100.

41 Maltais M, de Souto Barreto P, Moon SY, et al. Prospective association of white matter hyperintensity volume and frailty in older adults. Exp Gerontol 2019;118:51-4.

42 Serra-Prat M, Lorenzo I, Palomera E, et al. Intracellular water content in lean mass is associated with muscle strength, functional capacity, and frailty in community-dwelling elderly individuals. A crosssectional study. Nutrients 2019;11:661.

43 Tamaki K, Kusunoki H, Tsuji S, et al. The relationship between dietary habits and frailty in rural Japanese community-dwelling older adults: cross-sectional observation study using a brief self-administered dietary history questionnaire. Nutrients 2018;10:1982.

44 lizaka S. Frailty and body mass index are associated with biophysical properties of the skin in community-dwelling older adults. J Tissue Viability 2018;27:141-5.
45 Li CY, Al Snih S, Karmarkar A, et al. Early frailty transition predicts 15-year mortality among nondisabled older Mexican Americans. Ann Epidemiol 2018;28:362-7.

46 Zylberglait Lisigurski M, Bueno YA, Karanam C, et al. Healthcare utilization by frail, community-dwelling older veterans: a 1-year follow-up study. South Med J 2017;110:699-704.

47 Sampaio PYS, Sampaio RAC, Yamada M, et al. Comparison of frailty among Japanese, Brazilian Japanese descendants and Brazilian community-dwelling older women. Geriatr Gerontol Int 2015;15:762-9.

48 Garre-Olmo J, Calvó-Perxas L, López-Pousa S, et al. Prevalence of frailty phenotypes and risk of mortality in a community-dwelling elderly cohort. Age Ageing 2013;42:46-51.

49 Wang GC, Kao WHL, Murakami P, et al. Cytomegalovirus infection and the risk of mortality and frailty in older women: a prospective observational cohort study. Am J Epidemiol 2010;171:1144-52.

50 Crow RS, Lohman MC, Titus AJ, et al. Association of obesity and frailty in older adults: NHANES 1999-2004. J Nutr Health Aging 2019;23:138-44.

51 Hasegawa Y, Sakuramoto A, Sugita H, et al. Relationship between oral environment and frailty among older adults dwelling in a rural Japanese community: a cross-sectional observational study. BMC Oral Health 2019;19:23.

52 Satake S, Shimokata H, Senda K, et al. Validity of total Kihon checklist score for predicting the incidence of 3-year dependency and mortality in a community-dwelling older population. J Am Med Dir Assoc 2017;18:552.e1-552.e6.

53 Ballew SH, Chen Y, Daya NR, et al. Frailty, Kidney Function, and Polypharmacy: The Atherosclerosis Risk in Communities (ARIC) study. Am J Kidney Dis 2017;69:228-36.

54 Zaslavsky O, Rillamas-Sun E, Li W, et al. Association of dynamics in lean and fat mass measures with mortality in frail older women. $J$ Nutr Health Aging 2017;21:112-9.

55 Monin J, Doyle M, Levy B, et al. Spousal associations between frailty and depressive symptoms: longitudinal findings from the cardiovascular health study. J Am Geriatr Soc 2016;64:824-30.

56 Espinoza SE, Hazuda HP. Frailty prevalence and neighborhood residence in older Mexican Americans: the San Antonio longitudinal study of aging. J Am Geriatr Soc 2015;63:106-11.

57 Drubbel I, Bleijenberg N, Kranenburg G, et al. Identifying frailty: do the frailty index and Groningen frailty indicator cover different clinical perspectives? A cross-sectional study. BMC Fam Pract 2013;14:64.

58 Yao X, Hamilton RG, Weng N-ping, et al. Frailty is associated with impairment of vaccine-induced antibody response and increase in post-vaccination influenza infection in community-dwelling older adults. Vaccine 2011;29:5015-21.

59 Kiely DK, Cupples LA, Lipsitz LA. Validation and comparison of two frailty indexes: the mobilize Boston study. J Am Geriatr Soc 2009;57:1532-9.

60 Chaves PHM, Varadhan R, Lipsitz LA, et al. Physiological complexity underlying heart rate dynamics and frailty status in communitydwelling older women. J Am Geriatr Soc 2008;56:1698-703.

61 Ožić S, Vasiljev V, Ivković V, et al. Interventions aimed at loneliness and fall prevention reduce frailty in elderly urban population. Medicine 2020;99:e19145.

62 Potier F, Degryse JM, Bihin B, et al. Health and frailty among older spousal caregivers: an observational cohort study in Belgium. BMC Geriatr 2018;18:291. 26

63 Belisário MS, Dias FA, Pegorari MS, et al. Cross-Sectional study on the association between frailty and violence against communitydwelling elderly people in Brazil. Sao Paulo Med J 2018;136:10-19.

64 Hoeksema AR, Spoorenberg SLW, Peters LL, et al. Elderly with remaining teeth report less frailty and better quality of life than edentulous elderly: a cross-sectional study. Oral Dis 2017;23:526-36.

65 Turusheva A, Frolova E, Korystina E, et al. Do commonly used frailty models predict mortality, loss of autonomy and mental decline in older adults in northwestern Russia? A prospective cohort study. BMC Geriatr 2016;16:98.

66 Bastone AdeC, Ferriolli E, Teixeira CP, et al. Aerobic fitness and habitual physical activity in frail and Nonfrail community-dwelling elderly. J Phys Act Health 2015;12:1304-11.

67 Ruiz-Arregui L, Ávila-Funes JA, Amieva H, et al. The Coyoacán cohort study: design, methodology, and participants' characteristics of a Mexican study on nutritional and psychosocial markers of frailty. J Frailty Aging 2013;2:68-76.

68 Giudici KV, de Souto Barreto P, Soriano G, et al. Defining vitality: associations of three operational definitions of vitality with disability in instrumental activities of daily living and frailty among elderly over a 3-year follow-up (MAPT study). J Nutr Health Aging 2019;23:386-92. 
69 Xue QL, Bandeen-Roche K, Varadhan R, et al. Initial manifestations of frailty criteria and the development of frailty phenotype in the women's health and aging study II. J Gerontol A Biol Sci Med Sci 2008:63:984-90.

70 Min LC, Elliott MN, Wenger NS, et al. Higher vulnerable elders survey scores predict death and functional decline in vulnerable older people. J Am Geriatr Soc 2006;54:507-11.

71 Pegorari MS, Ruas G, Patrizzi LJ. Relationship between frailty and respiratory function in the community-dwelling elderly. Braz $J$ Phys Ther 2013;17:9-16.

72 Tian X, Wang C, Qiao X, et al. Association between pain and frailty among Chinese community-dwelling older adults: depression as a mediator and its interaction with pain. Pain 2018;159:306-13.

73 Freitas FFQ, Soares SM. Índice de vulnerabilidade clínicofuncional $\mathrm{E}$ as dimensões $\mathrm{dA}$ funcionalidade em idosos. Rev Rene 2019;20:e39746

74 Fhon JRS. A prevalência de quedas em idosos e a sua relação com a fragilidade e a capacidade funcional [dissertation]. Ribeirão Preto: Universidade de São Paulo, Escola de Enfermagem de Ribeirão Preto, 2011.

75 Ribeiro EG. Análise psicométrica do índice de vulnerabilidade clínico funcional 20 [dissertation]. Brazil: Belo Horizonte, 2018.

76 Ribeiro EG, Matozinhos FP, Guimarães GdeL, et al. Self-perceived health and clinical-functional vulnerability of the elderly in Belo Horizonte/Minas Gerais. Rev Bras Enferm 2018a;71 Suppl 2:860-7.

77 Ribeiro PCC, Neves ACC, Reis JC. Clinical-functional vulnerability in older adults and its impact on primary health care actions. Ver. Bras. Promoç. Saúde 2019;32:8366.

78 Marques SGS. Determinação do somatotipo e do nível de atividade física em idosos frágeis [dissertation]. São Paulo: Universidade de São Paulo, Escola de Artes, Ciências e Humanidades, 2019.
79 Fabrício-Wehbe SCC, Rodrigues RAP, Haas VJ, et al. Association of frailty in hospitalized and institutionalized elderly in the communitydwelling. Rev Bras Enferm 2016;69:691-6.

80 Santiago LM. Fragilidade em idosos no Brasil: identificação e análise de um instrumento de avaliação para ser utilizado na população do país [thesis]. Brazil. Rio de Janeiro 2013.

81 Neto GCF. Perfil sociodemográfico, condições de saúde e vulnerabilidade da população idosa de um município do Seridó do Rio Grande do Norte [completion of course work]. Brasil. Rio Grande do Norte 2019.

82 Balbinot G, Uscocovich KJSO. Risco de vulnerabilidade DOS idosos de uma unidade de saúde dA família no oeste paranaense. Rev. Saúde Públ. Paraná 2019;2:13-19.

83 Barbosa KTF. Vulnerabilidade física, social e programática de idosos atendidos na atenção primária de saúde do município de JP [dissertation]. Brazil. Paraiba 2015.

84 Lang IA, Hubbard RE, Andrew MK, et al. Neighborhood deprivation, individual socioeconomic status, and frailty in older adults. J Am Geriatr Soc 2009;57:1776-80.

85 Daniels R, van Rossum E, Beurskens A, et al. The predictive validity of three self-report screening instruments for identifying frail older people in the community. BMC Public Health 2012;12:69.

86 Fukutomi E, Okumiya K, Wada T, et al. Relationships between each category of 25-item frailty risk assessment (Kihon checklist) and newly certified older adults under long-term care insurance: a 24-month follow-up study in a rural community in Japan. Geriatr Gerontol Int 2015;15:864-71.

87 Yamaguchi M, Yamada $\mathrm{Y}$, Nanri $\mathrm{H}$, et al. Association between the frequency of protein-rich food intakes and Kihon-Checklist frailty indices in older Japanese adults: the Kyoto-Kameoka study. Nutrients 2018:10:84. 